\title{
Digital video games in education system-A Systematic Review
}

\author{
Anand Priyanka*, Raj Micheal** \\ *student, Masters in physiotherapy, Lovely Professional University, Punjab. \\ **Assistant professor, Lovely Professional University, Punjab.
}

\begin{abstract}
Introduction: The adult brain was once seen as a static organ but now it is clear that brain circuitry and organization is constantly changing with new experiences and learning. The past decade has seen a surge of interest in so-called 'brain training'. One creative and user interactive method of 'brain training' is "digital video games" also called "Serious games". Video games play a role in enhancing the learning as well as intelligence especially fluid intelligence in healthy individuals.
\end{abstract}

Aims and objectives: The paper overviews the educational relevance of video games on memory, cognitive and executive function which constitutes a person's fluid intelligence and reasoning ability.

Methods: The following databases were searched electronically: GOOGLE SCHOLAR, PUBMED, PEDRO, COCHRANE LIBRARY, MEDLINE, GAME STUDIES, PROQUEST and several others. The paper presents the most influential research on the subject based on an extensive search of the literature between years 2001 till 2013. Any articles other than English language were excluded.

Result and discussion: The articles were reviewed thoroughly. Certain studies showed a strong evidence towards improvement in learning, memory, attention, execution and fluid intelligence. Maximum articles showed improvement in learning (Mean $=0.8, N=20)$. However, on a negative perspective, video games also lead to aggression in behaviour in one of the studies.

Conclusion: The critical analysis was done and the articles were compared which led to the conclusion that using video games in education plays a major role in improving learning than the traditional learning system. The judicious use of video games should be incorporated in education system so as to avoid the negative effects such as aggression.

Keywords: fluid intelligence, attention, perception, cognition, execution and serious games.

\section{Background}

Digital games are a growing part of our culture; the global market is worth billions of dollars, related activities range from published magazines to spontaneous internet communities, and the impact of games play on young people has attracted significant interest from the popular media. Exploring games and education is inherently controversial. Games can seem uneducational. But in this review, we tried to bring out a new perspective of video games i.e. digital game based learning. A serious game or applied game is a game designed for a primary purpose other than pure entertainment. The "serious" adjective is generally prepended to refer to products used by industries like defense, education, scientific exploration, health care, emergency management, city planning, engineering, religion, and politics . examples include Dimenxian Evolver, Geography explorer, NIU Torcs, River City, Supercharged, Virtual Cell etc. So far we all know that video games are used for entertainment purpose. These are considered as leisure time activities. But serious digital video games can increase our intelligence especially fluid intelligence. Fluid intelligence is the capacity to think logically and solve problems in novel situations, independent of acquired knowledge. It is responsible for strategic thinking, planning, executive function, perception and cognition.

This review provides:

\section{Objectives}

- To collect various researches and articles available for the use of digital games for educational purpose.

- To critically analyse the literature available suggesting the use of video games for educational purpose.

- To provide an overview of the main developments in research into gaming and the educational relevance of video games, and a summary of the literature resulting from this research.

- To propose a new way of learning and increasing intelligence in the education system.

This study provides an evidence for incorporating digital video games in the education system as these are useful for learning purpose in addition to traditional learning methods and also analyses the pros and cons of using digital video games in detail. 


\section{Criteria For Selection Of Studies:}

\section{Methods}

- $\quad$ All articles other than English language were excluded.

- The articles published in databases like: GOOGLE SCHOLAR, PUBMED, PEDRO, COCHRANE LIBRARY, MEDLINE, GAME STUDIES, PROQUEST are only selected.

- The titles and abstracts of all reports were screened for the previously mentioned search criteria.

- All articles deemed 'relevant', 'dubious' or 'unknown' were examined in full text. If necessary, additional information was sought on the publisher's website or through correspondence with the authors.

- 20 articles were selected relevant to this review.

To further summarize our findings, we used the following levels of evidence (Sackett 2000; van Tulder 2003) of benefit, of no benefit, or of reduced benefit relative to the comparison treatment:

- $\quad$ Strong evidence - denotes consistent findings in multiple high quality randomised controlled trials

- Moderate evidence - denotes findings in a single, high quality randomised controlled trial or consistent findings in multiple low quality trials.

- $\quad$ Limited evidence - indicates a single low quality randomised trial.

- Unclear evidence - denotes inconsistent or contradictory results in multiple randomised trials.

- $\quad$ No evidence - means no studies were identified.

\section{Outcome Measures:}

The primary outcome measures include: learning, short term memory, long term memory, attention, execution, fluid intelligence and aggression.
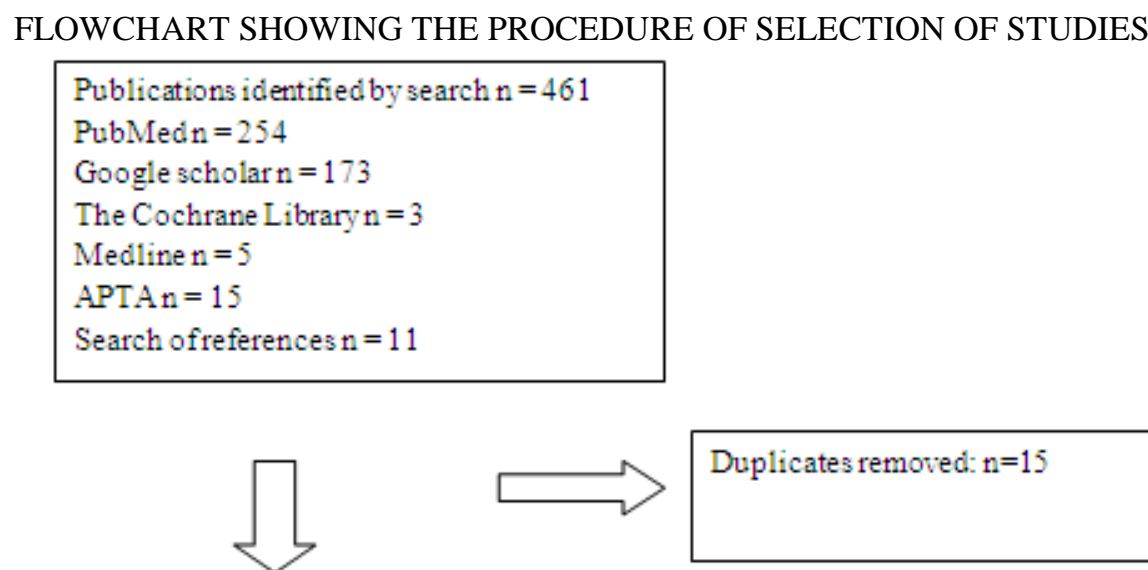

Duplicates removed: $\mathrm{n}=15$

Articles screened: $n=446$
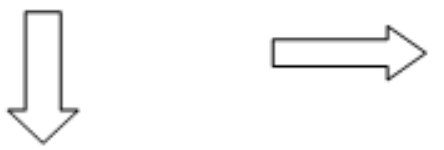

Articles not eligible: $n=409$

Articles assessed for eligibility: $\mathrm{n}=37$

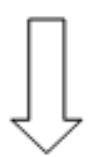

Articles excluded: $n=17$

Articles reporting digital video

games: $n=20$ 


\section{Effects Of Intervention}

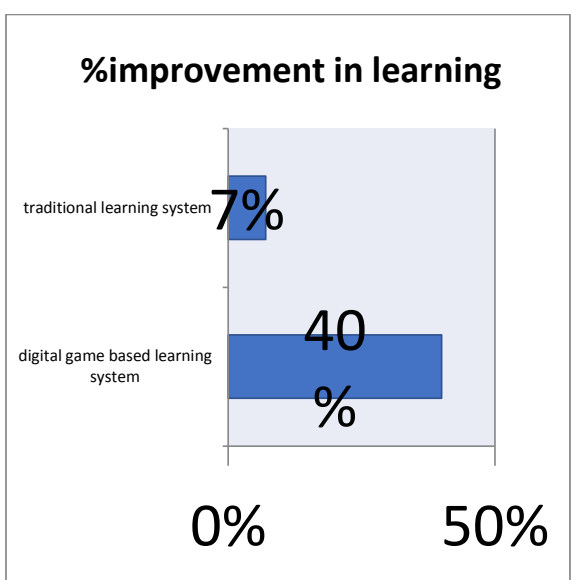

Figure 5.1

In a study by Gee et al, (figure 5.1) it was proved that there was $40 \%$ improvement in learning by digital game based learning methods while with traditional learning methods it was only $7 \%$.

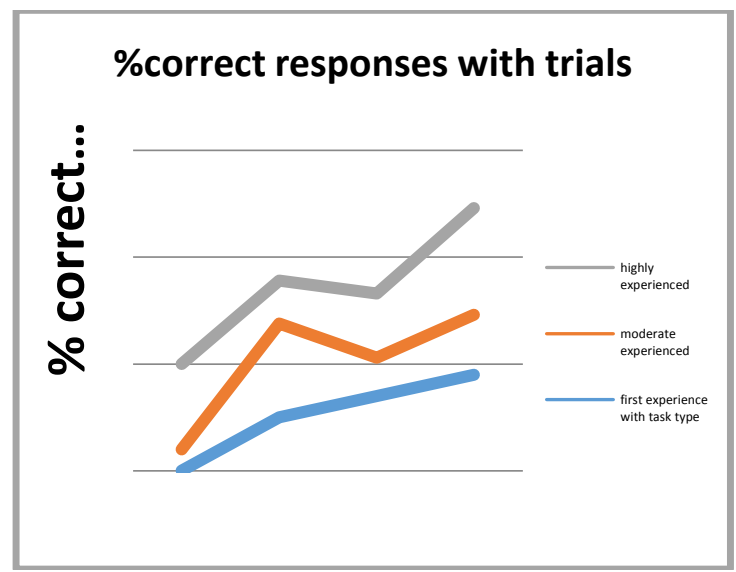

Figure 5.2

In a review by C.S Green et al, 2012, (figure 5.2) a series of different learning tasks were given to solve. Although experience with many tasks with the same underlying structure did not result in enhanced performance on trial number one, it did result in a substantial increase in the rate at which new tasks were learned.

In a study by Koepp et al in 1998, it was found that playing video games stimulates substantial dopamine release. As we know dopamine is a precursor to the memory storage event, playing video games can enhance memory.

In a study by McClean at al in 2001, digital game "Virtual Cell" on the topic of cell biology was being practiced by 238 college students. The learning outcome was inmproved by $40 \%$ over traditional lecture system. In one study by Squire et al in 2004, two groups each with 32 and 58 students respectively played an electrostatistics game called Supercharged. The control group improved their understanding by $15 \%$ while the gamers improved by $28 \%$. 


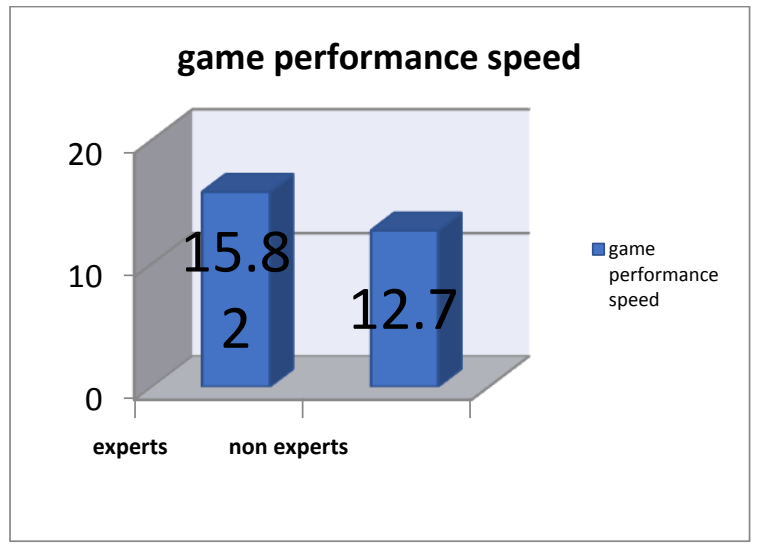

Figure 5.3

In a study by Boot et al in 2008, (figure 5.3) 82 participants were divided in three groups for digital video games. A no practice control group was also taken. The practice sessions of total $21.5 \mathrm{~h}$ were provided to the participants. The primary measure included the speed at which participants could track three items while maintaining near perfect accuracy. Experts far outperformed non-gamers in their ability to track at higher speeds.

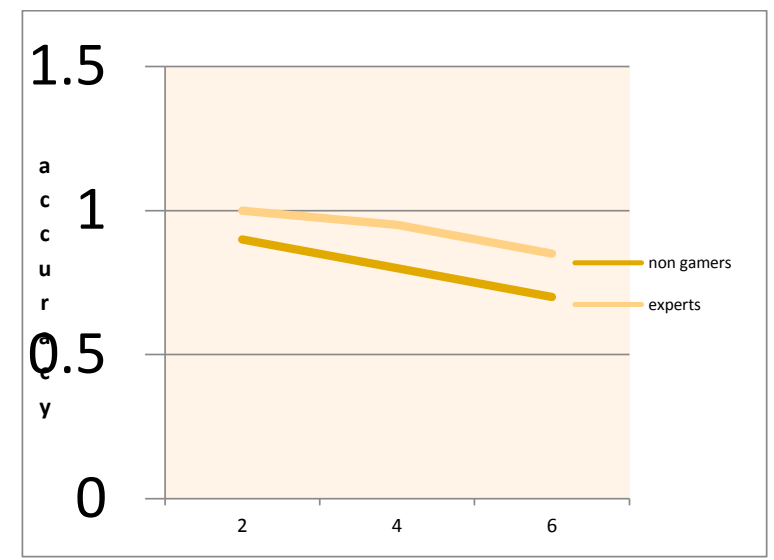

Figure 5.4

The accuracy was also measured in the study (figure 5.4) which suggested that there were increased accurate responses in experts than non-gamers.

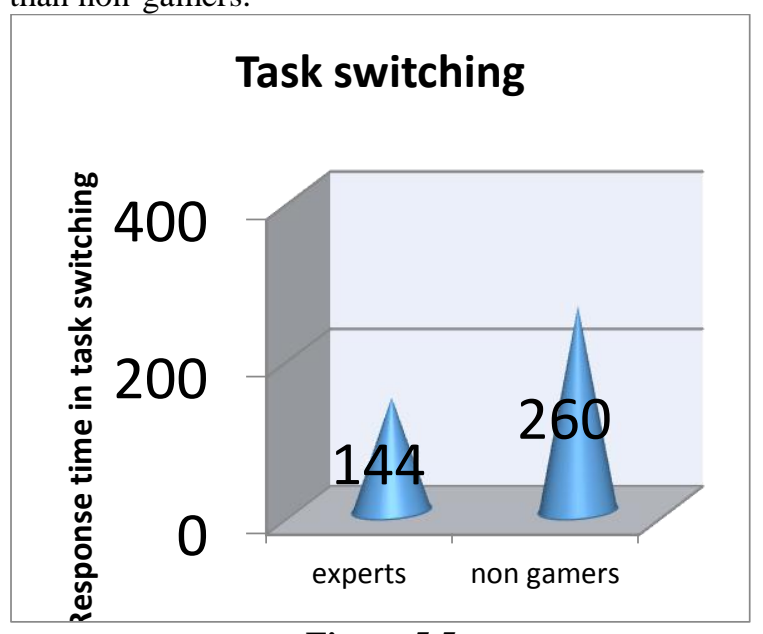

Figure 5.5

The execution of tasks or response time in task switching was measured in the same study (figure 5.5). Experts showed a smaller switch cost compared to non-gamers. 
In a study, of two groups, there was an improvement in understanding by $15 \%$ in control group $(\mathrm{N}=32)$ who learned via interactive lectures and teacher's demonstration while improvement was $28 \%$ in group $(\mathrm{N}=58)$ who learned via video game. (Mayo M, 2007).

\section{Critical Analysis}

Critical analysis was performed on the basis of strong evidence for the outcome measures and means were calculated for $\mathrm{N}=20$.

\begin{tabular}{|c|c|c|c|c|c|c|}
\hline & $\begin{array}{l}\text { Improvement } \\
\text { in learning }\end{array}$ & $\begin{array}{l}\text { Improvement } \\
\text { in attention }\end{array}$ & $\begin{array}{l}\text { Improvement } \\
\text { in memory }\end{array}$ & $\begin{array}{l}\text { Improvement in } \\
\text { execution }\end{array}$ & $\begin{array}{l}\text { Increased } \\
\text { aggression }\end{array}$ & $\begin{array}{l}\text { Improvement in } \\
\text { fluid intelligence }\end{array}$ \\
\hline $\begin{array}{l}\text { Mark: } \\
\text { Griffiths, } 2002\end{array}$ & Strong evidence & $\times$ & $x$ & $x$ & $x$ & $x$ \\
\hline $\begin{array}{l}\text { Kirriemuir J. , } \\
2002\end{array}$ & $\times$ & Strong evidence & $x$ & $x$ & $x$ & Strong evidence \\
\hline BECTA survey & Strong evidence & $x$ & $x$ & $\times$ & $x$ & Strong evidence \\
\hline $\begin{array}{l}\text { Miguel } \\
\text { Aguilera et al, } \\
2003\end{array}$ & Strong evidence & $\times$ & $x$ & $x$ & $x$ & Strong evidence \\
\hline Paul J., 2003 & Strong evidence & $x$ & $x$ & $x$ & $x$ & $x$ \\
\hline $\begin{array}{lll}\text { Paul } & \text { J. Gee, } \\
2004 & & \end{array}$ & Strong evidence & $x$ & $x$ & $x$ & $x$ & $x$ \\
\hline $\begin{array}{l}\text { Bucliley, } \mathrm{K} \text { et al, } \\
2006\end{array}$ & Strong evidence & & $x$ & $x$ & $\begin{array}{l}\text { Strong } \\
\text { evidence }\end{array}$ & $x$ \\
\hline Vogel et al, 2006 & Strong evidence & $x$ & $x$ & $x$ & $\times$ & $\times$ \\
\hline $\begin{array}{l}\text { Oblinger D, } \\
2006\end{array}$ & Strong evidence & Strong evidence & $x$ & Strong evidence & $x$ & Strong evidence \\
\hline $\begin{array}{l}\begin{array}{l}\text { Weber et al, } \\
2006\end{array} \text { } \\
\end{array}$ & Strong evidence & $x$ & $x$ & $x$ & $\begin{array}{l}\text { Strong } \\
\text { evidence }\end{array}$ & $x$ \\
\hline $\begin{array}{l}\text { Merrilea J. , } \\
2007\end{array}$ & Strong evidence & $x$ & $x$ & $x$ & $\times$ & $x$ \\
\hline $\begin{array}{l}\text { Begona gros. } \\
2007\end{array}$ & Strong evidence & Strong evidence & $x$ & $x$ & $x$ & Strong evidence \\
\hline Boot et al. , 2008 & $x$ & Strong evidence & Strong evidence & Strong evidence & $\times$ & $\times$ \\
\hline Jaeggi et al, 2008 & $\times$ & $x$ & $\times$ & $\times$ & $x$ & Strong evidence \\
\hline $\begin{array}{l}\text { Merrilea } \\
\text { Mayo et al, } 2009\end{array}$ & Strong evidence & $x$ & $x$ & $x$ & $x$ & $x$ \\
\hline Perrig et al, 2009 & $\times$ & $x$ & $\times$ & $\times$ & $x$ & Strong evidence \\
\hline Boot et al. , 2011 & Strong evidence & Strong evidence & $x$ & $x$ & $x$ & Strong evidence \\
\hline Green et al, 2012 & Strong evidence & Strong evidence & $x$ & $x$ & $x$ & $\times$ \\
\hline $\begin{array}{l}\text { Graafland M et } \\
\text { al, } 2012\end{array}$ & Strong evidence & Strong evidence & $x$ & $\times$ & $x$ & $x$ \\
\hline $\begin{array}{l}\text { Rondon et al, } \\
2013\end{array}$ & Strong evidence & $x$ & $x$ & $x$ & $x$ & $x$ \\
\hline
\end{tabular}

- $\quad$ The means of the above articles improving the outcomes are shown as follows:

\begin{tabular}{|l|l|}
\hline Outcome measures & Means of articles supporting the improvement $(\mathrm{N}=20)$ \\
\hline Learning & 0.8 \\
\hline Memory & 0.05 \\
\hline Attention & 0.4 \\
\hline Execution & 0.1 \\
\hline Aggression & 0.1 \\
\hline Fluid intelligence & 0.4 \\
\hline
\end{tabular}

- Thus, the results were in favour of digital game based learning especially cognitive learning > fluid intelligence $>$ attention $>$ execution $>$ memory. 


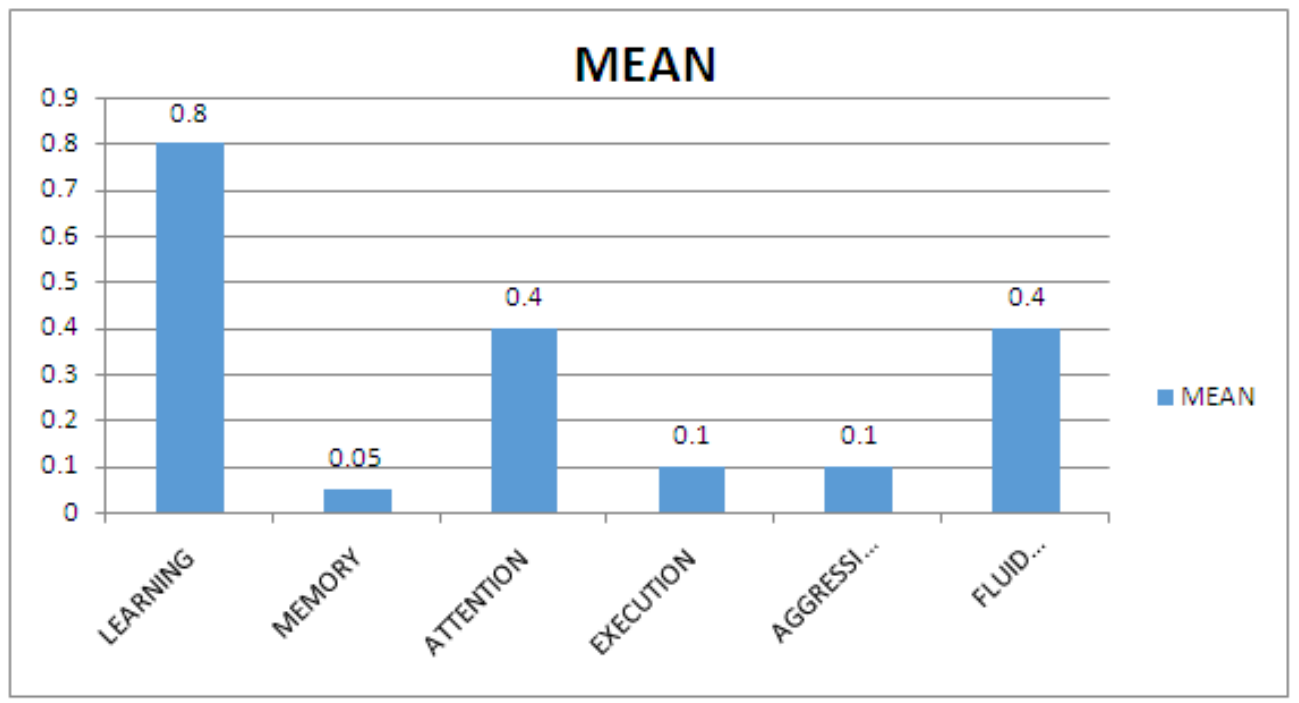

Graph to represent the means of articles supporting the improvement

\section{Discussion}

This review led to the results that video games can enhance learning and intelligence. The articles were reviewed thoroughly.

- Video games compared with traditional teaching methods are better for cognitive gains. (Vogel et al, 2006) $(\mathrm{z}=6.051, \mathrm{p}<.0001(\mathrm{~N}=8549))$.

- $\quad$ Edutainment is a new and imaginative method of learning. (Kirriemuir J).

- Video games cause activation of dorsal cognitive part $(\mathrm{p}<.027)$, rostral affective part $(\mathrm{p}<.003)$ and amygdala ( $\mathrm{p}<.014)$ reflecting a long term learning impact through video games.(Weber et al, 2006).

- Video games have the potential to directly provide massive parallel education in science and engineering (Merrilea J, 2007).

- Video games have a positive effect on memory, attention and executive control.(Boot et al, 2008)

- Video games help in development of skills like language skills, basic reading, math skills, and social skills in autistic children. (Griffiths M, 2002).

- Video games can be instrumental in acquiring abilities and skills like:

- Spatial perception and recognition.

- Development of visual attention.

$\circ \quad$ Development of inductive logic.

- Cognitive development.

- Development of complex skills.

- Iconic code construction. (Aguilera, 2003).

- $\quad$ Role playing in a digital video game improves learning. (Paul J, 2003).

- $\quad$ The design of the video game should be such that it is easily adaptable to normal people. (Gee, 2004).

- $\quad$ Short- and long-term benefits of cognitive training revealed a significant improvement on the trained task in the experimental group; $\mathrm{t}(31)=6.38$; $(\mathrm{p}<0.001)$. In contrast, there was no significant performance improvement in the active control group; $t$ (29) <1. (Susanne M. Jaeggi, 2011).

- Video games can improve cognition and perception.(Boot et al, 2011)

- Video games can also improve task switching, multi-tasking, and visual short-term memory tasks. (Green et al, 2012).

- Computer games have been effectively used to teach algebra and geometry (Corbett et al, 2001), biology, golfing skills and computer programming.

- A recent metaanalysis of effectiveness of using educational software programs found positive effects on both early reading development $(\mathrm{d}=0.35 ; \mathrm{N}=26)$ and math $(\mathrm{d}=0.45 ; \mathrm{N}=13)$ (Murphy et al, 2002).

- $\quad$ Video games also increase perceptual skills. (Rosser et al, 2004).

- $\quad$ Research has yet to prove that video games are intellectually harmful but on the contrary many studies defend their great importance in development of intellectual abilities. (Aguilera, 2003).

- Video games can yield a 7 to $40 \%$ positive learning increase over a lecture program. (Mayo et al, 2009).

- $\quad$ Serious games can be used for medical education and surgical skills training (Graafland M et al, 2012).

- On the negative perspective, video games also lead to aggression in behaviour, obesity and other health related problems. 


\section{Long term effects of video games:}

\section{Conclusion}

- Factual learning: Educational softwares focussed on practised routines to enhance the learning of specific concrete facts. This type of software can be incorporated in classrooms. Students will receive quick feedback about their performance and are able to repeat tasks until they are successful.

- Learning behaviours: Video games can also enhance learning of many types of complex behaviour by simulation and role playing.

- Changes in personality: As with the development of various well rehearsed knowledge structures, development of personality also occurs.

The implementation issues in the education system include:

- cost

- Are computer laboratories available?

- Is the right equipment available e.g.: joystick,

- Is technical support available for the games?

- Are there instructional designers available who can develop games?

- Is gaming integrated into the curriculum?

Following key points are noted:

1. Digital video games enhance intelligence, cognition, perception, attention to a great extent in comparison to the traditional teaching methods.

2. The role of teacher in structuring and framing the activity of the learner is crucial. Also, he requires some understanding of controls, menus and skills about the game.

3. Games have a significant advantage in developing motivation, skills and encourage collaboration.

4. Development of gaming softwares that incorporate the best features of educational and gaming techniques are required.

5. Development of game design, plot, character development, user interface design should be relevant to academic courses in education system (Kirriemuir, J, 2002).

6. Digital games can be used in various educational sectors: business, management, budgetary economics, accountancy, science and engineering. (Mayo M, 2007).

Hence we conclude that digital game based learning is a new era of education system. The game based learning should be incorporated in the education system according to relevant academic courses. The design and implementation should be as per the subjects offered. To avoid the negative impact of digital games on health, judicious use of games should be done.

\section{Future scope of the study}

- Many research studies can be done comparing the improvements in all the outcomes discussed in this review with traditional teaching methods vs game based digital learning.

- The game based learning can also be applied to patients with intellectual disabilities for their daily living.

\section{Bibliography}

[1]. Mark Griffiths. The educational benefits of Videogames. Nottingham; 2002.

[2]. Rondon et al. Computer game-based and traditional learning method: a comparison regarding students' knowledge retention. Brazil; 2013.

[3]. Graafland $\mathrm{M}$ et al. Systematic review of serious games for medical education and surgical skills training. Amsterdam; 2012.

[4]. Green et al. Learning, Attentional Control, and Action Review; 2012

[5]. Boot et al. Do action video games improve perception and cognition? USA; 2011

[6]. Perrig et al. Can We Improve Fluid Intelligence With Training on Working Memory in Persons With Intellectual Disabilities? Switzerland; 2009.

[7]. Merrilea J. Mayo et al. Video Games: A Route to Large-Scale STEM education. USA; 2009.

[8]. Robert J. Sternberg. Increasing fluid intelligence is possible after all. Medford; 2008.

[9]. Boot et al. The effects of video game playing on attention, memory, and executive control. USA; 2008.

[10]. Begona gros. Digital games in education: the design of game based learning environment. Barcelona; 2007.

[11]. Merrilea J. games for science and engineering education.USA; 2007.

[12]. Oblinger D. Simulations, Games, and Learning; 2006.

[13]. Kirriemuir J. The relevance of video games and gaming consoles to the Higher and Further Education learning experience. UK; 2002

[14]. Kirriemuir J. Use of Computer and Video Games in the Classroom. UK

[15]. Miguel de Aguilera et al. Video Games and Education. Spain; 2003

[16]. Paul J. What Video Games Have to Teach Us About Learning and Literacy. Madison; 2003

[17]. Paul J. Gee. Learning by design: Games as learning machines. Madison;2004.

[18]. Buckley, K et al. Theoretical model of the effects and consequences of playing video games. NJ-USA; 2006.

[19]. Vogel et al. Computer gaming and interactive simulations for learning: a meta-analysis. Central Florida; 2006.

[20]. Oblinger D. Simulations, Games, and Learning; 2006 